\title{
O impacto do tipo de amostragem no controle de qualidade na lavra
}

\author{
(Influence of the sampling method on grade control)
}

\footnotetext{
Agenor de Faria Junior

Mestrando em Eng. Mineral, EPUSP.

E-mail: agenor.faria@bunge.com
}

Giorgio de Tomi

Engenheiro de Minas, Professor Associado, EPUSP.

E-mail: gdetomi@usp.br

Lilia M. Sant'Agostino

Professora, Dra., IGC-USP.
E-mail: agostino@usp.br

João Felipe Coimbra Leite Costa

Engenheiro de Minas, Professor, Dr., DEMIN, UFRGS. E-mail: jfelipe@ufrgs.br

\section{Resumo}

Um dos grandes desafios enfrentados pela indústria mineral é a dificuldade em prover à usina de beneficiamento minérios que possuam as especificações de teores adequadas para seu bom desempenho. O conhecimento geológico das diferentes litologias que formam uma jazida é etapa fundamental para a garantia da qualidade esperada do minério, mas não é suficiente. Após o conhecimento dos diferentes domínios geológicos, que abrange uma série de atividades exploratórias e tem como produto final um modelo tridimensional de blocos, obtido com a utilização de técnicas geoestatísticas, outra atividade igualmente importante é a estimativa de teores, que atribui teores das variáveis de interesse a cada bloco através de técnicas de interpolação como a krigagem. Esse artigo contém a análise comparativa de estimativas dos teores obtidos por três diferentes tipos de amostragem para o controle de qualidade da lavra e apresenta os resultados de uma aplicação prática de estudo de caso na unidade litológica denominada Carbonatito Branco, na Mina de Cajati da Empresa Bunge Fertilizantes S/A, localizada a sudeste do Estado de São Paulo.

Palavras-chave: Arranjo de sondagem, estimativa de teores, lavra de carbonatito, controle de qualidade na lavra.

\section{Abstract \\ One of the major challenges for the mining industry is to supply the processing plant with ore that meets its specifications for maximizes production. This can only be achieved if proper knowledge of the geological domains of the orebody is acquired. However, this condition is not sufficient: once the geological domains of the orebody are properly known, it is also necessary to model the geological grades using estimation techniques such as kriging. The challenge for mining companies is to establish sampling processes and techniques that allow the appropriate estimation of the geological grades of the mined out ore. This paper presents a comparative analysis between three sampling methods and their impact on the estimation of the geological grade at the mine face in a case study carried out at the Cajati mine of Bunge Fertilizantes S/A, located in Sao Paulo, Brazil.}

Keywords: Drill sampling, grade estimation, mining of carbonatites, ore quality control. 


\section{Introdução}

A obtenção do conhecimento geológico de uma jazida é uma das etapas mais importantes desenvolvidas em qualquer empreendimento mineral, abrangendo atividades exploratórias como: geofísica, mapeamento geológico e sondagens rotativas a diamante. Tais etapas têm como objetivo avaliar o arranjo e as intersecções de litologias, através da integração de informações e análise dos testemunhos de sondagem. Esse conhecimento oferece condições para a criação de um modelo geológico tridimensional (Hustrulid \& Kuchta, 1995), com os domínios geológicos individualizados, e proporciona, também, a estimativa dos teores in situ. As informações obtidas sobre a continuidade da mineralização, que seja potencialmente econômica, são pouco adequadas para o planejamento da mina no longo prazo e insuficientes do ponto de vista da operação de lavra, (Revuelta \& Jimeno, 1997).

Desde que o empreendimento mineral tenha a possibilidade de ir adiante, a malha de sondagem deve ser adensada, obtendo-se uma quantidade muito maior de amostras, possibilitando a validação dos dados obtidos por ocasião da fase de exploração e aumentando, significativamente, a confiabilidade na estimativa de teores, (Revuelta \& Jimeno, 1997). Pode-se, então, utilizar técnicas geoestatísticas como uma importante ferramenta para auxiliar a criação de um modelo tridimensional de blocos que represente a jazida e obedeça, estritamente, ao modelo geológico anteriormente obtido, onde, a cada bloco, serão inseridos atributos como teores das varáveis de interesse, parâmetros geotécnicos, metalúrgicos, financeiros, entre outros.

Finalmente, durante a fase de lavra, uma amostragem de maior detalhe se faz necessária para estabelecer o controle de teores, cujos objetivos podem ser muito variados, como, por exemplo, aprimorar a precisão dos modelos de estimativa de longo prazo, em que as informações foram obtidas a partir de amostras de sondagem, detectar, no minério, possível presença de zonas com baixos teores etc. (Revuelta \& Jimeno, 1997). Nessa fase, podem-se utilizar amostras de sondagem rotativa a diamante, amostras de canaletas, amostras volumétricas das frentes de lavra ou, ainda, amostras de pó-de-perfuratriz. Todas essas ações vão depender de condições operacionais ou dos recursos financeiros disponíveis.

O presente artigo se refere a estudos de apoio à operação de lavra na Mina de Cajati, operada pela Bunge Fertilizantes S/A, e tem, como objetivo, a comparação de resultados de blocos krigados, para fins de controle de qualidade da mina, através da análise de três diferentes tipos de amostragens realizadas em um domínio geológico denominado Carbonatito Branco (CBR): sondagens rotativas a diamante (SRD), sondagens de circulação reversa (SCR) e amostras de pó-de-perfuratriz (APO).

\section{Estudo de caso}

A Mina de Cajati está localizada a sudeste do Estado de São Paulo, entre São Paulo e Curitiba, às margens da BR 116, e é lavrada desde a década de 1940, como indicado na Figura 1.

A mina é lavrada à céu aberto, em bancadas de 10 e $20 \mathrm{~m}$ de altura, onde se extrai o carbonatito mineralizado em apatita. O minério passa por diferentes etapas de tratamento, entre elas, britagem, homogeneização, moagem, etc, até se obter o concentrado final de rocha fosfática.

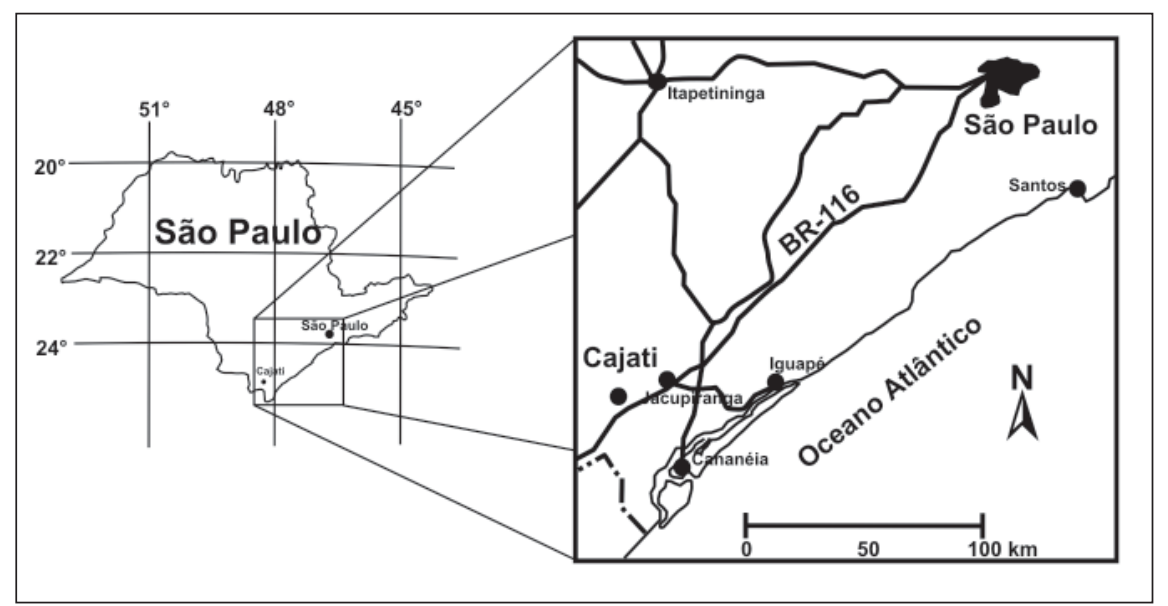

Figura 1 - Mapa de localização da Mina de Cajati.
O modelo geológico da Mina de Cajati, mostrado na Figura 2, é formado por doze litologias (ou domínios geológicos), que são lavradas em diferentes proporções para a formação das pilhas de homogeneização que alimentam a usina de beneficiamento. Entre as diferentes litologias, o Carbonatito Branco (CBR) foi selecionado para o presente estudo de caso. Esse tipo de carbonatito pode ser lavrado, individualmente, ou em misturas com os outros domínios geológicos.

Segundo Ferreira (2007), o CBR é um carbonatito maciço inequigranular médio a muito grosso, localmente pegmatítico e porfirítico, com fenocristais de magnetita muito grossa $(>5 \mathrm{~cm})$. Sua composição é, predominantemente, calcítica ( 75-90\%), podendo ocorrer lentes intercaladas de carbonatos magnesianos, apatita fina acicular esverdeada concentrada em bolsões radiais ( $7 \%)$, flogopita fina verde euédrica $(\sim 5 \%)$, magnetita média a muito grossa euédrica $(\sim 2-5 \%)$ e sulfetos associados à magnetita. O contato com as litologias adjacentes é interdigitado e localmente gradativo.

\section{Metodologia}

A variável selecionada para estudo foi o $\mathrm{P}_{2} \mathrm{O}_{5}$, que ocorre no mineral apatita. A comparação entre os resultados obtidos, nos diferentes tipos de amostragens, foi desenvolvida de acordo com as seguintes atividades: 
i. Seleção das amostras contidas no domínio geológico, sendo tais amostras obtidas através de diferentes métodos de amostragem.

ii. Separação dos blocos do modelo, onde, na vizinhança local, os três tipos de amostras estão presentes.

iii. Análise estatística dos valores obtidos com cada método amostral.

iv. Variografia e krigagem de blocos com cada conjunto de amostras.

v. Comparação dos resultados de cada modelo gerado com cada conjunto de amostras.

As amostras SRD foram obtidas através de campanhas de sondagens realizadas ao longo dos anos de operação da mina, com os objetivos principais de delineamento dos domínios geológicos e de estimativa de teores. Os furos de sondagens estão distribuídos em uma malha irregular e possuem diâmetro 2,0 polegadas.

As amostras SCR foram coletadas a cada três metros perfurados em furos inclinados a $60^{\circ}$ graus, orientados na direção $\mathrm{N} 153^{\circ}$, com diâmetro de 5,5 polegadas, distribuídos em uma malha regular de 25 x 25 metros. Os furos foram realizados por uma perfuratriz Atlas Copco Explorac R50, utilizando método rotopercursivo, com martelo de fundo (DTH). Essa perfuratriz possui um quarteador Jones instalado, proporcionando a primeira redução da massa da amostra, junto à fase de coleta.

As amostras APO são coletadas, rotineiramente, durante a atividade de perfuração primária para desmonte de rocha na mina, em furos verticais, distribuídos em malha regular de 3,0 x 4,5 m, executados por perfuratrizes Atlas Copco ROC D7, ROC D9 e ROC F9, e tem como finalidade o controle de teores na lavra no curtíssimo prazo. Operacionalmente, esse tipo de amostragem possui vantagem sobre os outros dois tipos, uma vez que a perfuração primária é uma fase do processo de produção, ou seja, de qualquer maneira, a perfuração precisa ser realizada e a decisão de realizar, amostragem ou não é uma questão gerencial.

As etapas de separação das amostras, de acordo com a unidade litológica, variografia e krigagem dos blocos, foram feitas utilizando o programa computacional Datamine Studio ${ }^{\circledR} 2$. As análises estatísticas foram realizadas com o programa Excel ${ }^{\circledR}$.
No total, a base de dados SRD é formada por 22 furos de diferentes atitudes e totalizam 138 amostras, com comprimento médio de 4,9 m.

Os 15 furos SCR totalizam 160 amostras com comprimento médio de 2,93 m. As 673 amostras APO possuem comprimento médio de 10,75 m.

Para uma eficiente comparação entre os três tipos de amostragem, foi selecionada uma parte da unidade CBR, onde as diferentes amostras estivessem presentes. A Figura 3 mostra a localização das amostras rebatidas em um plano horizontal e a posição relativa dos furos no interior do domínio CBR.

Os testemunhos das amostras SRD foram serrados ao meio, sendo uma das metades arquivada e a outra metade preparada para análises químicas, seguindo etapas conjugadas de cominuição e quarteamento. As amostras de SCR e APO não passaram pela etapa de britagem por serem constituídas de pó-de-perfuratriz. Todas as amostras tiveram suas massas reduzidas em quarteadores Jones, até se obter a quantidade de $200 \mathrm{~g}$. Dessa quantidade foram retirados $30 \mathrm{~g}$ para a confecção de pastilhas fundidas e posterior análise por fluorescência de RX.

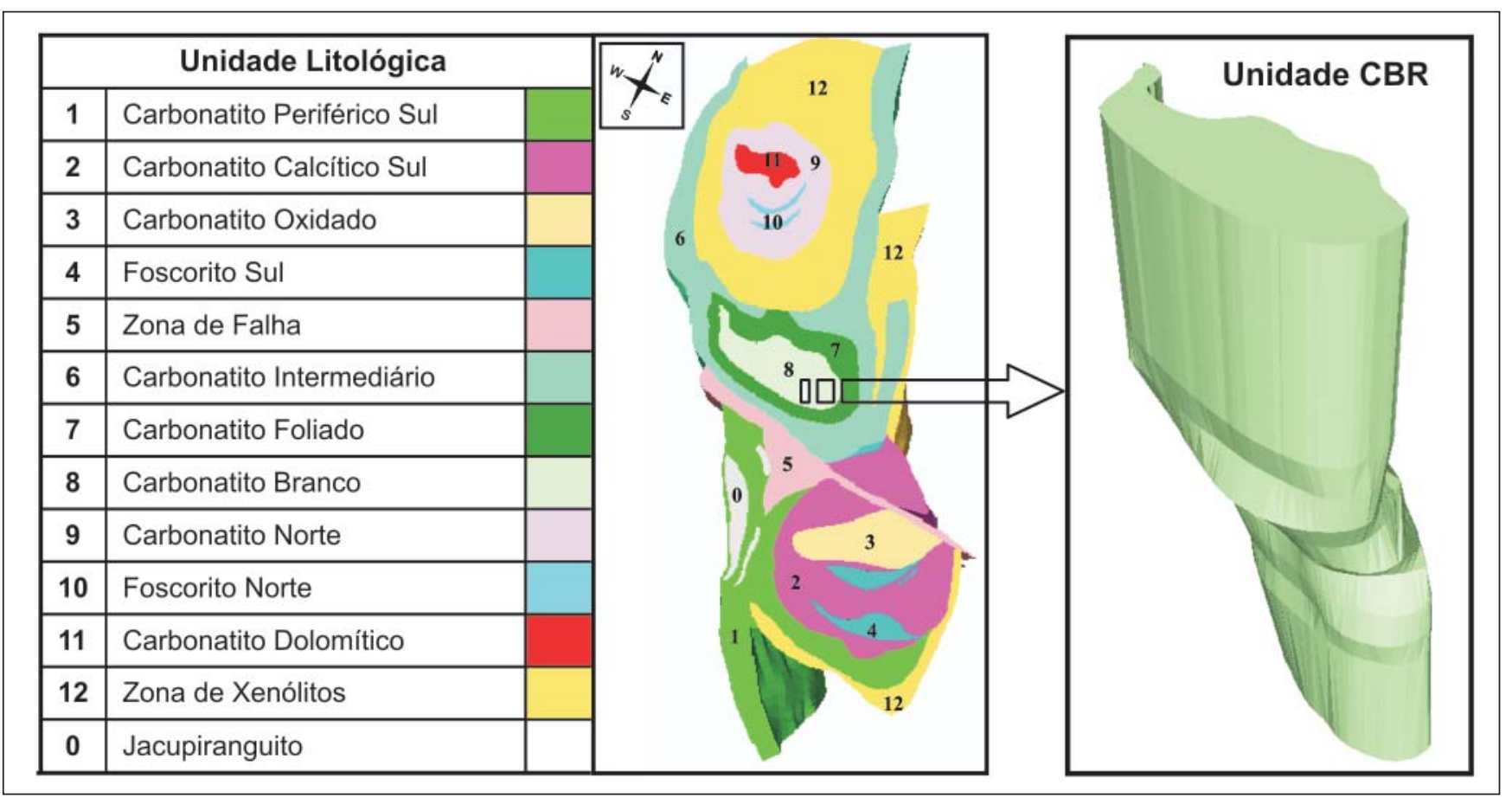

Figura 2 - Modelo geológico da Mina de Cajati. (Saito et al., 2004). 
O impacto do tipo de amostragem no controle de qualidade na lavra

\section{Resultados e discussão}

A análise estatística dos três grupos de amostras mostra valores muito semelhantes quanto à média e à variação, com maiores variância e desvio-padrão para as amostras de APO, consequência de sua distribuição espacial. (Tabela 1).

As distribuições de teores de cada grupo de amostras podem ser vistas, individualmente, na Figura 4, onde podem ser percebidas sutis diferenças, embora com parâmetros principais de distribuição similares e perfis, aproximadamente, de distribuição normal. Os valores das amostras SRD mostram distribuição simétrica e mais espalhada para os limites máximo e mínimo; os valores das amostras SCR parecem indicar duas populações misturadas; e, para as amostras APO, com um conjunto de valores cinco vezes maior que as demais, observa-se uma distribuição mais concentrada em torno da média.

Para a estimativa de teores por krigagem, é necessário um modelo de semivariograma. A análise variográfica dos conjuntos de amostras foi feita, inicialmente, com a geração de mapas de variogramas, que têm, como finalidade, identificar as direções em que os teores exibam maior continuidade espacial. A Figura 5 mostra os mapas de variogramas obtidos.
Os semivariogramas, corriqueiramente chamados de variogramas (Andriotti, 2003), obtidos de acordo com as direções indicadas pelos mapas de variogramas, apresentam anisotropia geométrica, que aparece quando se obtêm diferentes variogramas ao longo de diversas direções da jazida. Isto significa que, ao invés de obter uma área de busca isotrópica (círculo ou esfera), obtém-se uma zona elíptica ou elipsoidal, (Isaaks \& Srivastava, 1989). A Figura 6 mostra os variogramas obtidos.

Tabela 1 - Resumo estatístico das amostras.

\begin{tabular}{c|c|c|c}
\hline Elemento estatístico & $\mathbf{P}_{2} \mathbf{O}_{5} \mathbf{S R D}$ & $\mathbf{P}_{2} \mathbf{O}_{5} \mathbf{S C R}$ & $\mathbf{P}_{2} \mathbf{O}_{5} \mathbf{A P O}$ \\
\hline Média & 4.58 & 4.32 & 4.56 \\
\hline Variância & 2.72 & 1.96 & 1.05 \\
\hline Desvio-padrão & 1.65 & 1.40 & 1.02 \\
\hline Mínimo & 0.95 & 1.14 & 1.07 \\
\hline Máximo & 9.77 & 9.31 & 9.66 \\
\hline Coeficiente de variação & 0.36 & 0.32 & 0.22 \\
\hline Quantidade de amostras & 138 & 160 & 673 \\
\hline
\end{tabular}

Onde:

$\boldsymbol{P}_{2} \boldsymbol{O}_{5} \boldsymbol{S R D}$ - Teor de $\mathrm{P}_{2} \mathrm{O}_{5}$ das amostras SRD.

$\boldsymbol{P}_{2} \mathrm{O}_{5} \mathbf{S C R}$ - Teor de $\mathrm{P}_{2} \mathrm{O}_{5}$ das amostras SCR.

$\boldsymbol{P}_{2} \mathrm{O}_{5} \mathbf{A P O}$ - Teor de $\mathrm{P}_{2} \mathrm{O}_{5}$ das amostras APO.
A partir da obtenção dos variogramas, é possível o estabelecimento de parâmetros de krigagem, uma técnica largamente utilizada na avaliação de jazidas para estimativa do valor de uma variável regionalizada em um ponto ou bloco. Tal técnica possui, como principal característica, a precisão local das estimativas, mas com perda da precisão global, devido ao efeito de suavização (Matheron, 1963).

Para a estimativa dos teores dos blocos, cujas dimensões são de $10 \mathrm{x}$ 10 x 10 (m, m, m), nas direções X, Y e

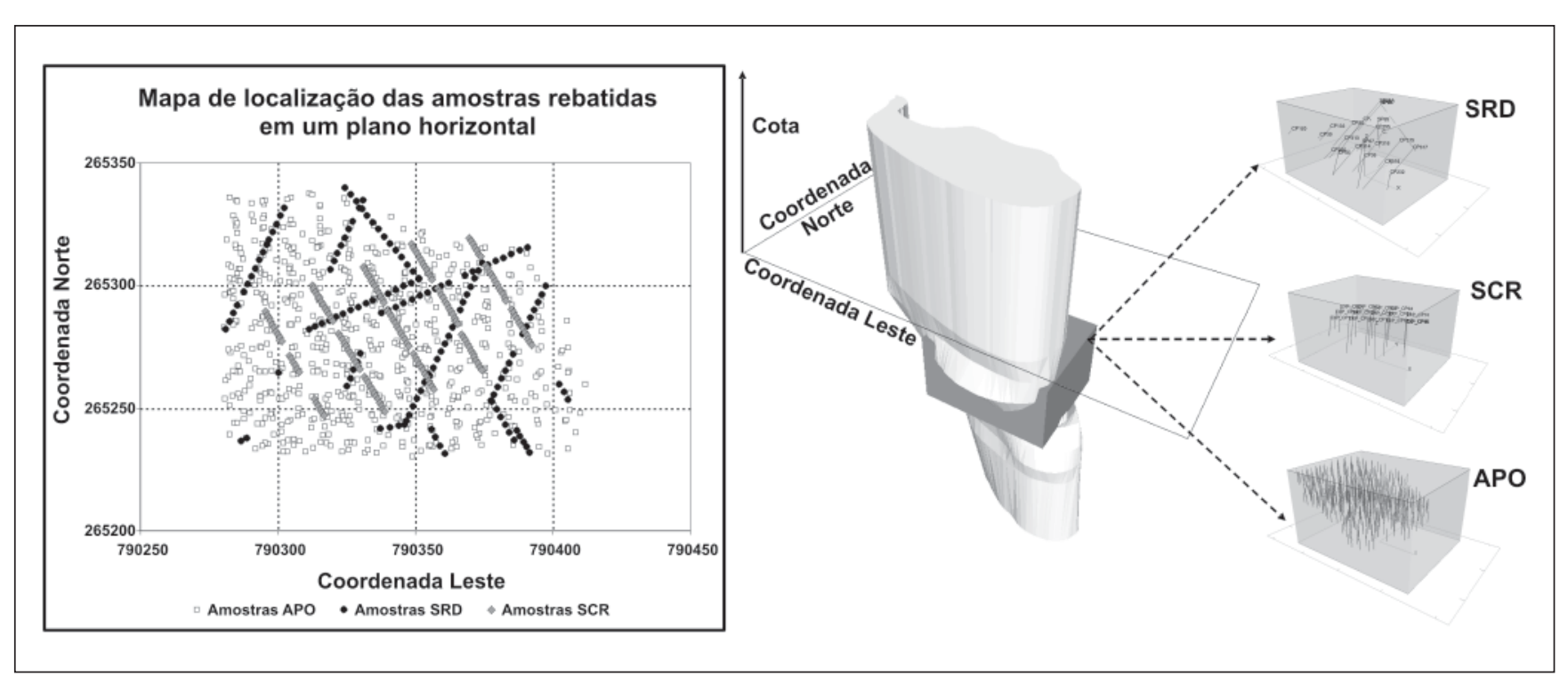

Figura 3 - Localização das amostras. 
Z, utilizou-se a amplitude máxima dos variogramas, além de busca por octantes, onde a região central do ponto ou bloco a ser estimado é dividida em oito setores. Essa medida evita que sejam selecionadas somente amostras muito próximas, caracterizando agrupamento de pontos (Isaaks \& Srivastava, 1989).

Os parâmetros utilizados, na krigagem dos blocos, são mostrados na Tabela 2.

No total, foram krigados 804 blocos com as amostras SRD, 333 com as amostras SCR e 758 com as amostras APO. A Tabela 3 mostra um resumo estatístico dos blocos krigados.

A verificação dos resultados da krigagem foi feita através da construção de gráficos de deriva nas direções NS, WE e vertical, onde são comparados os valores médios das amostras em um setor com os teores dos blocos krigados com tais amostras no mesmo setor. Os gráficos mostrados nas Figuras 7, 8 e 9, feitos em intervalos de $10 \mathrm{~m}$ em $10 \mathrm{~m}$, nas direções citadas, atestam a boa qualidade da krigagem, pois os teores dos blocos apresentam as mesmas tendências que os teores das amostras utilizadas.

Embora os resultados da krigagem tenham apresentado teores médios de $\mathrm{P}_{2} \mathrm{O}_{5}$ variando de 4,54\% (SRD), 4,28\% (SCR) e 4,53\% (APO), portanto, relativamente próximos, pode-se notar grandes diferenças quando analisados bloco a bloco, como mostrado na Figura 10, que apresenta uma seção horizontal na cota -75 m, nos três modelos krigados pelos seus respectivos grupos de amostras.

A amostragem SCR forneceu um modelo com características de teores de blocos algo inferior à SRD, enquanto a
APO tende para uma maior similaridade de teores.

As amostras de SRD possuem, como principal característica, a excelência de sua representatividade. Dessas amostras, pode-se obter grande número de informações como, por exemplo, contatos geológicos ou aspectos geotécnicos. Comparativamente, as amostras de sondagem rotativa são as que possuem maior dificuldade de obtenção, devido a fatores como custos relativos elevados e dificuldades operacionais (posicionamento, produtividade, etc), tornando difícil sua conciliação com as atividades de operação de lavra, podendo, inclusive inviabilizar sua aplicabilidade para fins de controle de qualidade da lavra no curto prazo.

A obtenção de amostras, através de circulação reversa, possui, em termos

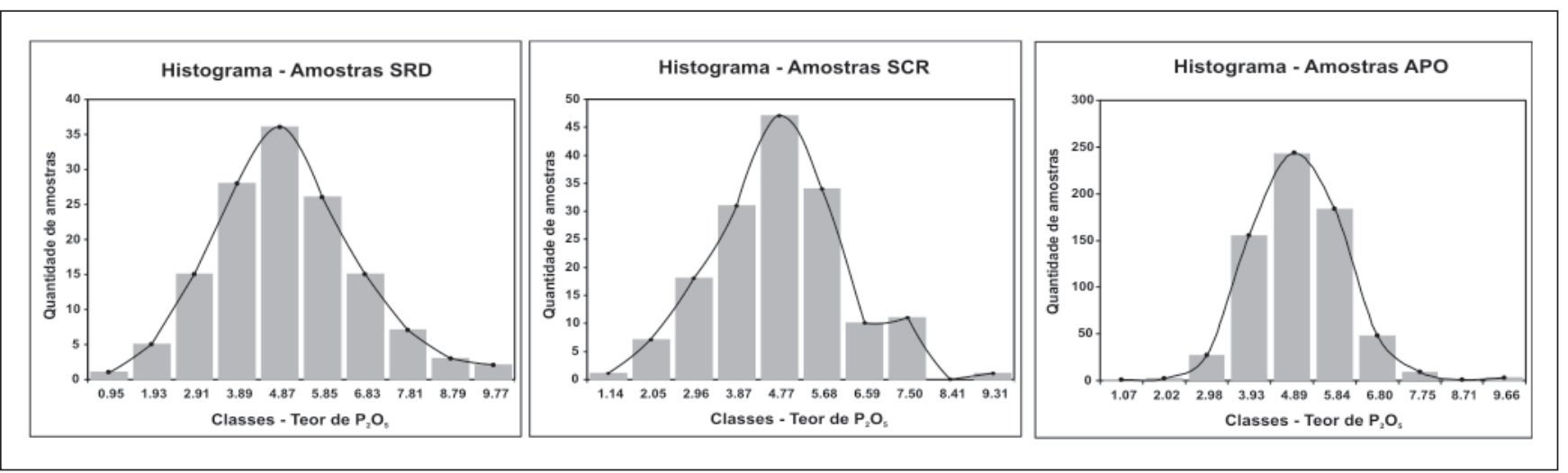

Figura 4 - Histogramas dos três tipos de amostragem.

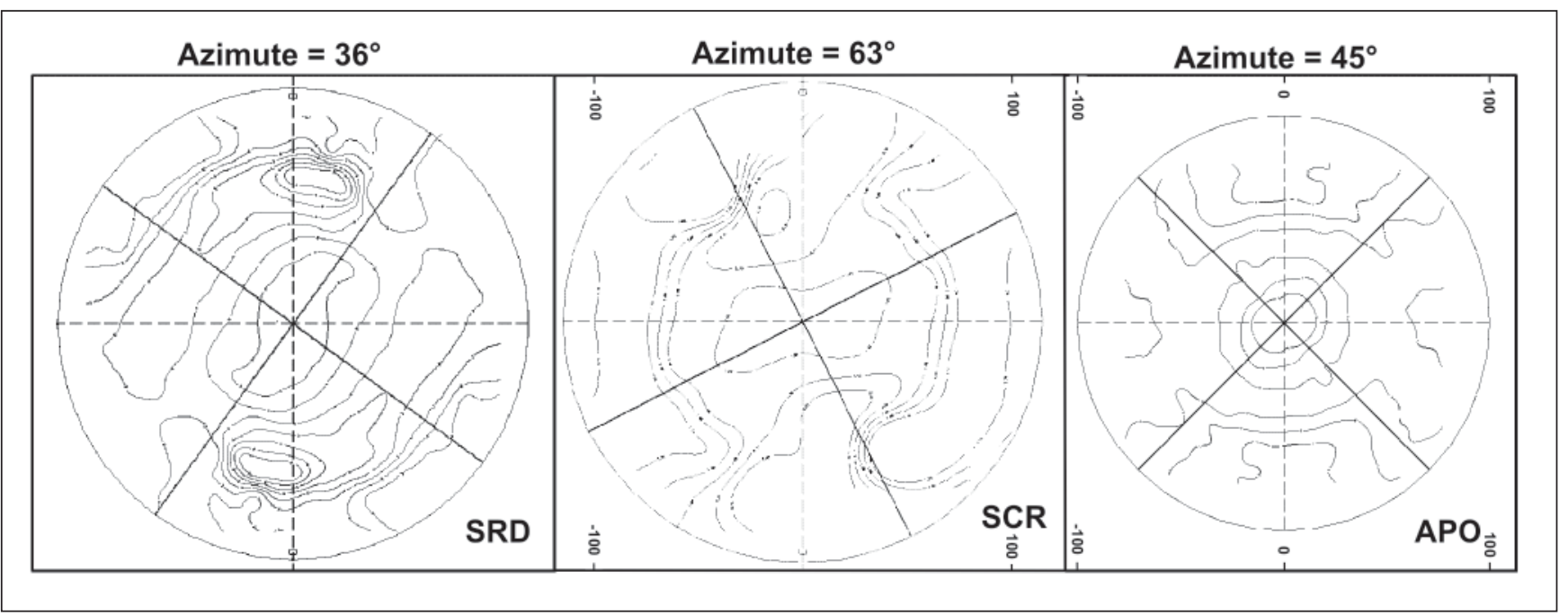

Figura 5 - Mapas de variograma dos três grupos de amostras. 
operacionais, maior facilidade que a obtenção das amostras de sondagem rotativa a diamante. Geralmente, as operações de amostragem podem ser mais facilmente conduzidas concomitantemente às operações de lavra.

As amostras APO possuem, indiscutivelmente, menor custo e maior facilidade de obtenção, quando comparadas com as amostras de SRD ou SCR, pois, de qualquer forma, os furos para desmonte de rocha sempre serão executados, além do fato de que o desem- penho dos equipamentos utilizados para perfuração de rocha estará associado aos demais equipamentos que executam a lavra. Isto significa que a atividade de amostragem não exige esforços adicionais por parte das operações de lavra, eliminando, assim, a necessidade de uma decisão gerencial sobre coletar amostras ou não.

Embora os três métodos de amostragem tenham mostrado resultados relativamente semelhantes, a obtenção de amostras de SCR e APO necessita de alguns cuidados, no que se refere aos procedimentos de coleta. No caso das amostras SCR, a maior dificuldade encontrada está relacionada ao controle do tamanho das amostras obtidas, o que está relacionado, especificamente, ao tipo de equipamento utilizado. Esse equipamento proporciona perdas significativas das partículas finas e ao processo de redução da amostra efetuado no próprio equipamento, podendo causar um viés que prejudicará a representatividade e o objetivo da amostragem. Neste caso,

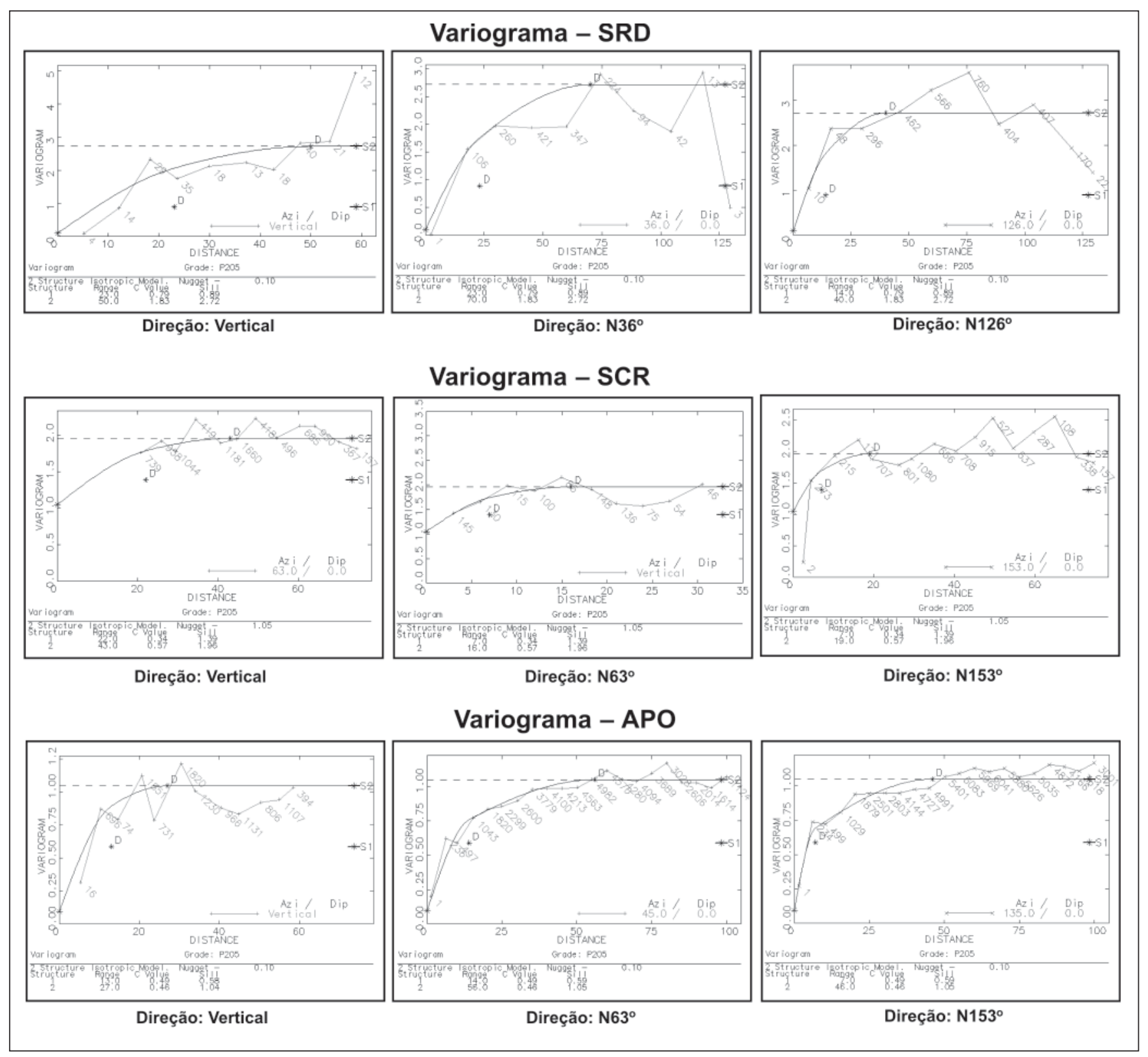

Figura 6 - Variograma dos três grupos de amostras. 
Agenor de Faria Junior et al.

as amostras de APO não são afetadas por esses fatores, proporcionando maior semelhança entre os resultados dessas amostras e os resultados das amostras SRD, reconhecidamente mais eficientes.

As amostras de APO são coletadas manualmente, o que afeta a probabilidade das partículas que constituem a amostra representarem o furo amostrado. Segundo Grigorieff et al. (2002), isto faz com que as partículas existentes no furo a ser amostrado não tenham a mesma probabilidade de pertencerem àquela amostra coletada. Quando a condição de eqüiprobabilidade não se cumpre, temos um espécime (ou exemplar), ao invés de amostra (Sironvalle, 2002).

\section{Conclusões}

Com base nos estudos comparativos feitos nos três tipos de amostragem, conclui-se que os métodos de amostragem apresentaram resultados consistentes, pois, além de apresentaram valores muito próximos, tanto das amostras, quanto dos blocos krigados, os gráficos de deriva mostrados anteriormente indicam que foi possível a obtenção de uma boa estimativa de teores. A amostragem mais adensada e obtida por técnicas diferentes mostrou, nesse estudo de caso, importantes diferenças na distribuição relativa de teores nos blocos de minério.

Portanto, para o estabelecimento de um eficiente controle de qualidade na lavra, a escolha do tipo de amostragem a ser implementado é uma decisão que deverá ser tomada analisando
Tabela 2 - Parâmetros de krigagem.

\begin{tabular}{c|c|c|c|c}
\hline \multicolumn{2}{c|}{ Parâmetros de krigagem } & \multicolumn{3}{c}{ Amostras } \\
\hline \multicolumn{2}{|c|}{ Elementos } & SRD & SCR & APO \\
\hline \multirow{3}{*}{$\begin{array}{c}\text { Distância } \\
\text { em metros }\end{array}$} & $\mathrm{X}$ & 40 & 19 & 46 \\
\cline { 2 - 5 } & $\mathrm{Y}$ & 70 & 43 & 56 \\
\cline { 2 - 5 } & $\mathrm{Z}$ & 50 & 16 & 27 \\
\hline \multirow{4}{*}{ Amostras } & Azimute & 36 & 63 & 45 \\
\cline { 2 - 5 } & Máximo por octantes & 8 & 8 & 8 \\
\cline { 2 - 5 } & Nónimo de octantes & 2 & 2 & 2 \\
\cline { 2 - 5 } & Mínimo por blocos & 4 & 4 & 4 \\
\cline { 2 - 5 } & Máximo por blocos & 64 & 64 & 64 \\
\hline
\end{tabular}

Tabela 3 - Resumo estatístico dos blocos krigados pelos diferentes grupos de amostras.

\begin{tabular}{c|c|c|c}
\hline Elemento estatístico & $\mathrm{P}_{2} \mathrm{O}_{5} \mathrm{SRD}$ & $\mathrm{P}_{2} \mathrm{O}_{5} \mathrm{SCR}$ & $\mathrm{P}_{2} \mathrm{O}_{5}$ APO \\
\hline Média & 4.54 & 4.28 & 4.53 \\
\hline Variância & 0.89 & 0.32 & 0.27 \\
\hline Desvio-padrão & 0.94 & 0.56 & 0.52 \\
\hline Mínimo & 2.43 & 2.72 & 2.88 \\
\hline Máximo & 7.85 & 5.72 & 6.19 \\
\hline Coeficiente de variação & 0.21 & 0.13 & 0.12 \\
\hline Quantidade de amostras & 804 & 333 & 758 \\
\hline
\end{tabular}

Onde:

$\boldsymbol{P}_{2} \boldsymbol{O}_{5} \boldsymbol{S R D}$ - Teor de $\mathrm{P}_{2} \mathrm{O}_{5}$ dos blocos krigados com as amostras $S R D$.

$\boldsymbol{P}_{2} \boldsymbol{O}_{5} \mathbf{S C R}$ - Teor de $P_{2} O_{5}$ dos blocos krigados com as amostras $S C R$.

$\boldsymbol{P}_{2} \mathrm{O}_{5} \mathbf{A P O}$ - Teor de $\mathrm{P}_{2} \mathrm{O}_{5}$ dos blocos krigados com as amostras APO.

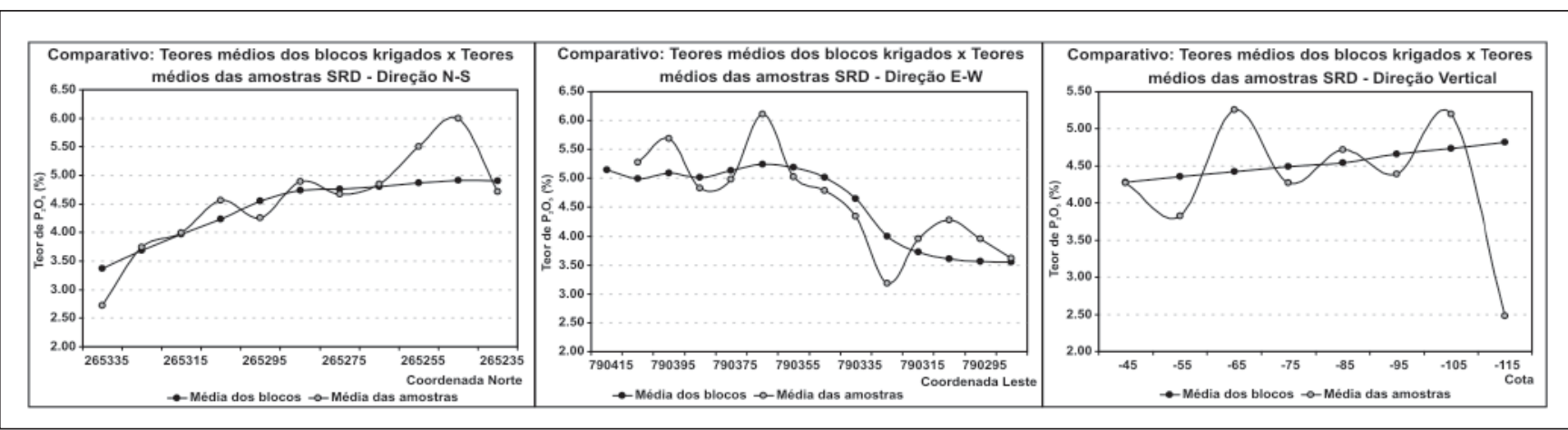

Figura 7 - Verificação dos resultados da krigagem de blocos com as amostras SRD. 


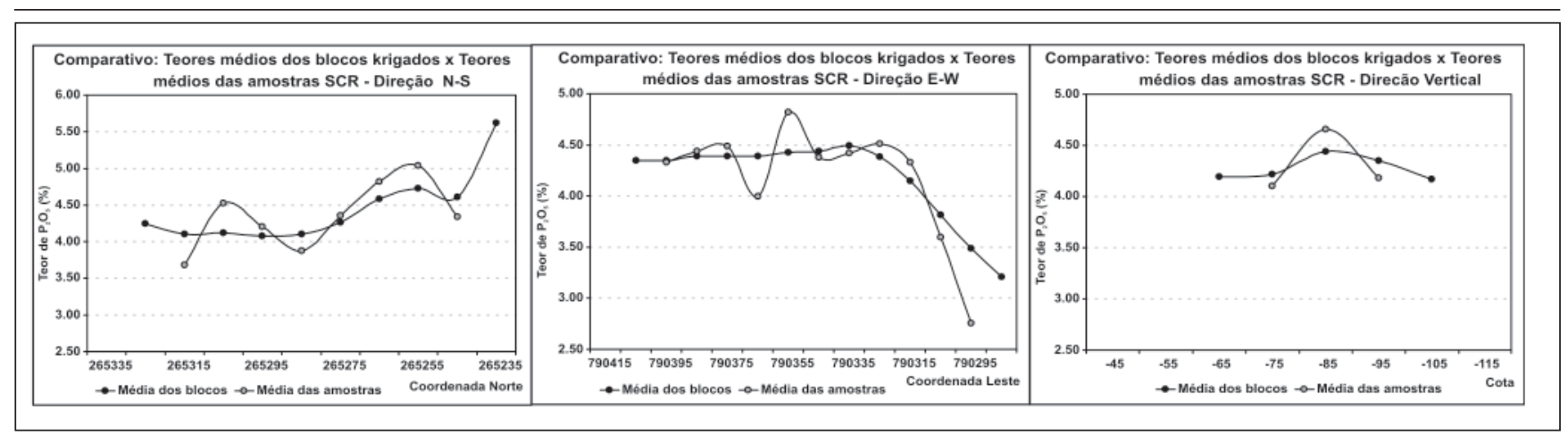

Figura 8 - Verificação dos resultados da krigagem de blocos com as amostras SRC.

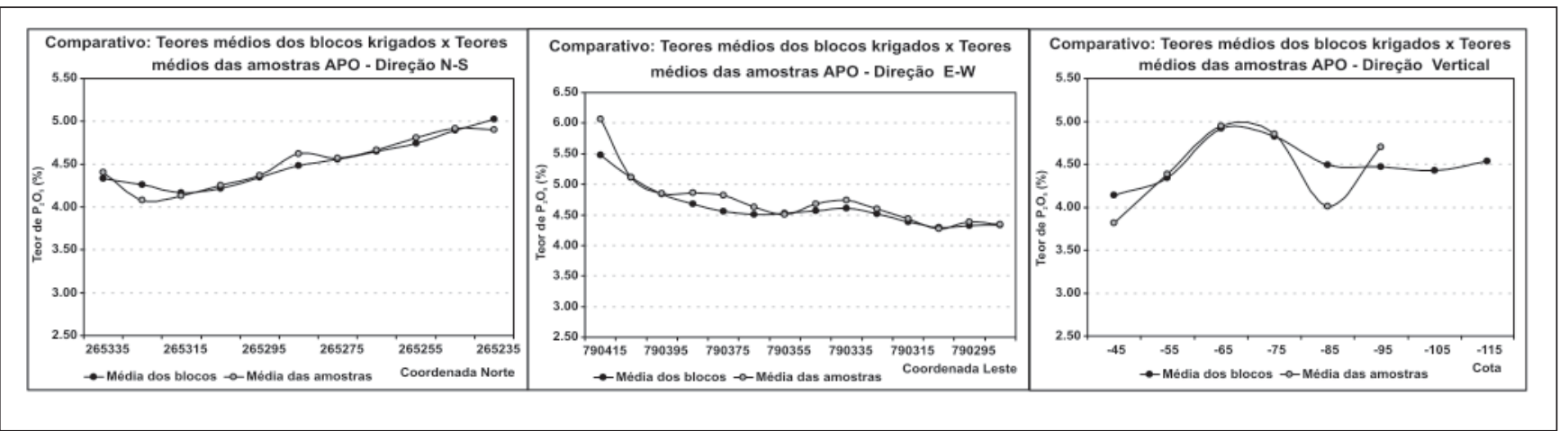

Figura 9 - Verificação dos resultados da krigagem de blocos com as amostras APO.

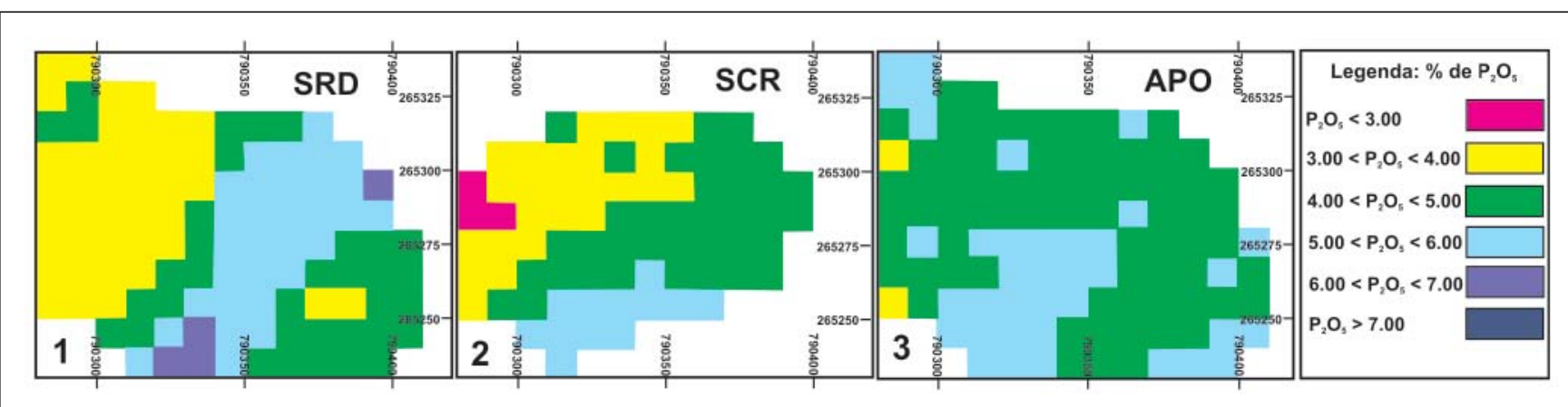

Figura 10 - Comparativo entre os blocos krigados pelos diferentes grupos de amostras. Cota -75m.

vários fatores como, por exemplo, o objetivo da amostragem, as facilidades operacionais, a adequação do método de amostragem à operação da mina, a disponibilidade financeira, entre outros.

\section{Referências bibiliográficas}

ANDRIOTTI, J. L. S. Fundamentos de estatística e geoestatística. São Leopoldo:Unisinos, 2003.165p.

FERREIRA, T. C. Avaliação dos atributos geológicos, mineralógicos, químicos e estruturais de corpos carbonatíticos da mina de apatita de Cajati, SP: Implicações no modelo de lavra. São Paulo: Instituto de Geociências, Universidade de São Paulo, 2007. 82p. (Trabalho de Conclusão de Curso de Graduação).

GRIGORIEFF, A., COSTA, J. F. C. L., KOPPE, J. O problema de amostragem manual na indústria mineral. REM-Revista Escola de Minas, v. 55, n.3, p. 229-233, jul. set. 2002.

HUSTRUILD, W., KUCHTA, M. Open pit mine planning \& design. Fundamentals. Rotterdam: A.A.Balkema, 1995. v. 1. 636p.

ISAAKS, E. H., SRIVASTAVA, R. M. An introduction to applied geoestatistics. New York: Oxford University Press, 1989.561p.

MATHERON, G. Principles of geostatistics. Economic Geology, v. 58, p. 1246-1266, 1963.

SAITO, M.M., BARROS, G., BONÁS, T.B., BETTENCOURT, J.S. Mapeamento geológico de detalhe da mina de Cajati (SP): modelo conceitual e aplicação à lavra, produção e beneficiamento. In: CONGRESSO BRASILEIRO DE GEOLOGIA, 42. Anais... Araxá: SBG, 2004. p. 785-786. 1 CD-ROM.

REVUELTA, M. B., JIMENO, C. L. Manual de evaluacion y diseño de explotaciones mineras. Madrid: Entorno Gráfico S.L., 1997. 708p.

SIRONVALLE, M. A. A. Introducción al mustreo minero. Santiago: Instituto de Ingenieros de Minas de Chile, 2002.83p.

Artigo recebido em 06/01/2009 e aprovado em 22/05/2009. 